\title{
INCREASED ACTIVITY OF ORNITHINE DECARBOXYLASE IN GOLDFISH FOLLOWING OPTIC NERVE CRUSH
}

\author{
SHINICHI KOHSAKA, MICHAL SCHWARTZ* and BERNARD W. AGRANOFF** \\ Department of Biological Chemistry and Mental Health Research Institute, University of Michigan, Ann \\ Arbor, Mich. 48109 (U.S.A.)
}

(Accepted December 19th, 1980)

Key words: goldfish — retina - ornithine decarboxylase - NGF — regeneration

\section{SUMMARY}

Ornithine decarboxylase (ODC) activity increased in goldfish retina, brain, and kidney several days following unilateral intraorbital optic nerve crush. Activity in both retinas followed a similar time course, an elevation being first detectable 3 days following crush, maximal on day 5 and returning to control levels by day 7 . Increases were significantly higher in the retina on the lesioned side than in control retina. If one eye was surgically removed, a more prolonged elevation of ODC activity was seen in the remaining eye than was observed in control retinas following contralateral nerve crush. Sham operation or behavioral stress secondary to aversive electrical shock did not lead to significant increases in ODC activity in brain or retina.

Explants of retinas whose optic nerve had been crushed 10-14 days prior to explantation, as well as those derived from the unlesioned side, showed increases in ODC activity following addition of $\beta$-NGF to the medium. The response was greater in post-crush retinas than in control retinas.

These results taken together suggest an increased responsiveness of the regenerating retina to stimuli that lead to increased ODC activity. While the nature of the in vivo signal(s) may be complex, it is inferred that degenerative changes in the distal stump play a significant role.

\section{INTRODUCTION}

Ongoing studies in this laboratory on the goldfish retina following crush of its optic nerve have demonstrated unilateral enhancement of RNA and RNA precursor metabolism $^{3,6}$ as well as of de novo synthesis of retinal microtubular protein ${ }^{4,10}$.

* Present address: Department of Neurobiology, The Weizmann Institute of Science, Rehovot, Israel.

** To whom correspondence should be addressed at: Neüroscience Laboratory Building, University of Michigan, 1103 East Huron, Ann Arbor, Mich. 48109, U.S.A. 
Polyamines, including putrescine, spermidine and spermine, have been implicated in a variety of hyperplastic and hypertrophic processes in which macromolecular synthesis is enhanced ${ }^{15,19,24}$. A special role in the nervous system has been suggested by experiments that indicate that putrescine, the product of ornithine decarboxylation, is transported axonally by the regenerating, but not by the intact nerve goldfish optic nerve ${ }^{13}$. We here explore the possible role of polyamines in the regenerating optic nerve, by measuring the activity of ornithine decarboxylase (ODC, EC 4.1.1.17), a rate-limiting enzyme in their formation.

\section{MATERIALS AND METHODS}

\section{Materials}

L- $\left[1-{ }^{14} \mathrm{C}\right]$ ornithine hydrochloride $(59 \mathrm{mCi} / \mathrm{mmol})$ was obtained from the Amersham Corporation (Arlington Heigths, Ill.). Mouse $2.5 \mathrm{~S}$ nerve growth factor ( $\beta$-NGF) was the generous gift of Dr. E. Shooter, Stanford University. Rabbit anti-NGF antiserum was obtained from Collaborative Research (Waltham, Mass.).

\section{Animals}

Goldfish (Carassius auratus), 6-7 cm in body length, obtained from Ozark Fisheries (Stoutland, Mo.) were anesthetized with tricaine methane sulfonate prior to the surgical procedures. Intraorbital crush of the right optic nerve was performed as previously described ${ }^{10}$. In sham-operated fish the nerve was exposed, but forceps were not closed on the nerve. Behavioral stress was induced by maintaining the fish in a shuttle box and administering 120 pulse electric shocks (AC $3.5 \mathrm{~V}$ ) at $10 \mathrm{sec}$ intervals 1 . Following the various treatments, fish were stored in groups of $30-80$ in 30 gallon tanks at $20-22{ }^{\circ} \mathrm{C}$ and were fed daily until sacrifice.

\section{Explant cultures}

Ten to fourteen days following optic nerve crush, retinas were removed from both normal (N) and crushed sides (PC) and cut into $0.5 \mathrm{~mm}$ squares as previously described ${ }^{16}$. The retinal explants were placed in culture dishes coated with poly-Llysine in Leibowitz nutrient (L-15) medium supplemented with the following at final concentration: $20 \mathrm{mM}$ HEPES ( $\mathrm{N}$-2-hydroxyethylpiperazine- $\mathrm{N}^{\prime}$-ethanesulfonic acid, pH 7.2), $0.1 \mathrm{mM} 5^{\prime}$-FudR (5'-fluorodeoxyuridine), $0.2 \mathrm{mM}$ uridine and $0.1 \mathrm{mg} / \mathrm{ml}$ gentamycin sulfate. Fetal calf serum (FCS), usually added to cultures was deleted, since the presence of ODC inducing factors might obscure effects of added NGF. Following culture at $20-22^{\circ} \mathrm{C}$ for various times, dishes were gently rinsed 3 times with phosphate buffer saline and then drained and stored at $-20^{\circ} \mathrm{C}$ prior to $\mathrm{ODC}$ assay as described below.

\section{$O D C$ assay}

Tissues were homogenized in $50 \mathrm{mM}$ Tris $\cdot \mathrm{HCl}$ buffer ( $\mathrm{pH}$ 7.6) containing $1 \mathrm{mM}$ dithiothreitol and $100 \mu \mathrm{M}$ pyridoxal phosphate in a Teflon glass homogenizer. The homogenates were centrifuged at $30,000 \times g$ for $20 \mathrm{~min}$ and the resulting supernatants 
were used for ODC assay, measured according to the method of Oka and Perry ${ }^{22}$ with minor modifications. Briefly, the enzyme assay was carried out in rubber-stoppered tubes that were fitted with an inverted center well which contained one-fourth of a 2.1 $\mathrm{cm}$ diameter glass-fiber filter (Whatman, Clifton, N.J.), premoistened with $10 \mu 1$ of $40 \% \mathrm{KOH}$. The reaction mixture (final vol., $0.5 \mathrm{ml}$ ) consisted of $50 \mathrm{mM}$ Tris $\cdot \mathrm{HCl}$ buffer (pH 7.6), $5 \mathrm{mM}$ dithiothreitol, $100 \mu \mathrm{M}$ pyridoxal phosphate, $4 \mathrm{mM}$ EDTA, $0.1 \%$ bovine serum albumin, $100 \mu \mathrm{M}$ of L-[1-14 C]ornithine hydrochloride $(0.5 \mu \mathrm{Ci})$ and the tissue supernatant fraction. Following incubation at $37^{\circ} \mathrm{C}$ for $1 \mathrm{~h}$ the reaction was terminated by tipping in $0.5 \mathrm{ml}$ of $10 \mathrm{~N} \mathrm{H}_{2} \mathrm{SO}_{4}$ from a side arm. The samples were then incubated for an additional hour to complete the ${ }^{14} \mathrm{CO}_{2}$ absorption. The glass filters were removed and the radioactivity of the trapped carbonate was measured in 10 $\mathrm{ml}$ of toluene-Triton scintillant containing $4 \mathrm{~g}$ of PPO and $0.1 \mathrm{~g}$ of dimethyl POPOP/1. Protein was determined by the method of Lowry et al. ${ }^{17}$.

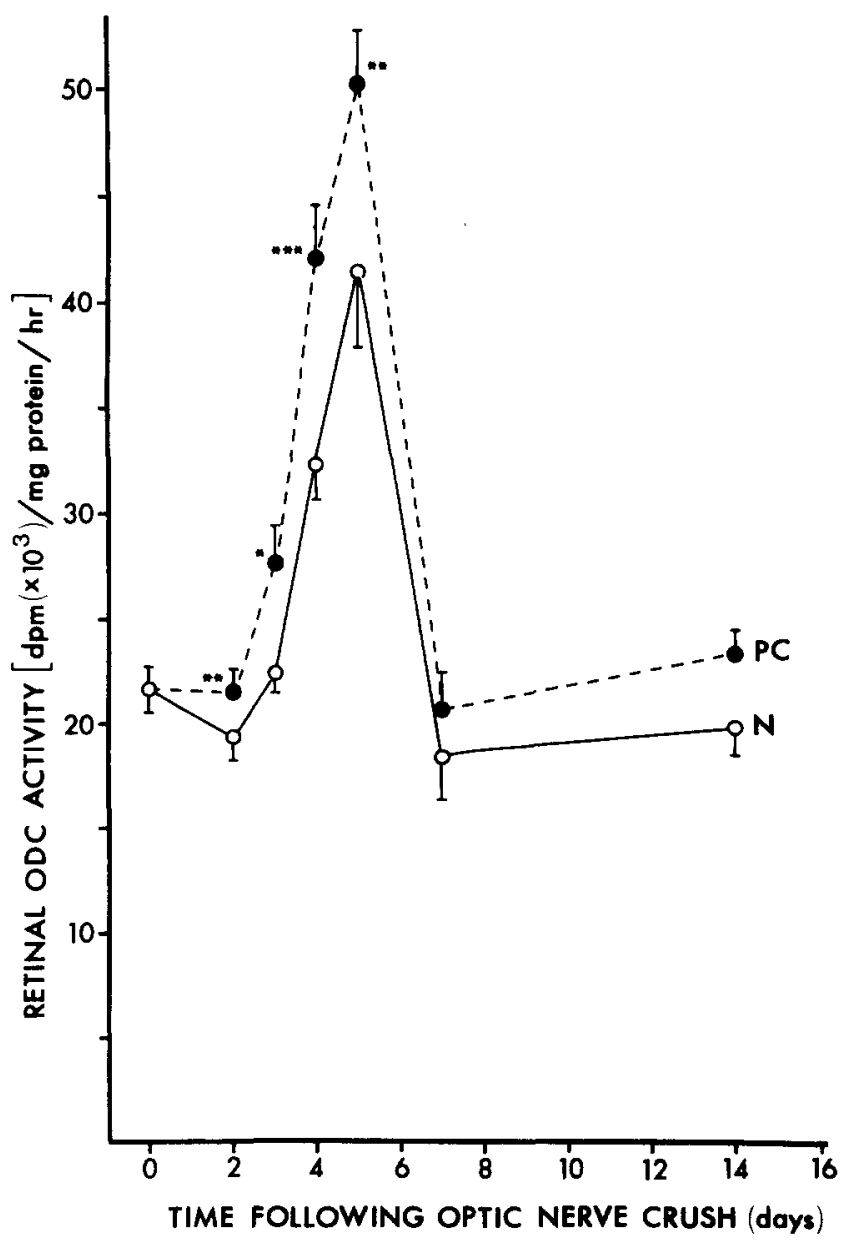

Fig. 1. Retinal ODC levels following unilateral optic nerve crush. At different times following optic nerve crush, $\mathrm{ODC}$ activity was measured in post-crush $(\mathrm{O} ; \mathrm{PC})$ and normal $(\mathrm{O} ; \mathrm{N})$ retinas. Each point represents mean \pm S.E.M. obtained from 3-9 groups of 5 pooled retinas. The $P C$ retinal values with asterisks are significantly higher than those of $\mathrm{N}$ retinas $\left(^{*} P<0.05 ;{ }^{* *} P<0.01\right.$; $\left.^{* *} P<0.005\right)$. 
RESULTS

$O D C$ activities in normal and post-crush retinas

ODC activity was measurably increased 3 days following crush, became maximal by day 5 and returned to the control level by day 7 (Fig. 1). While changes in the ODC activity in the retinas on the unoperated side ('normal', or $N$ ) showed a pattern similar to those in post-crush (PC) retinas, the ODC activity in the PC retinas were significantly higher than those of the $\mathrm{N}$ retinas. ODC activities in brain and kidney were also higher after optic nerve crush than those of non-treated control fish at 4 days post-crush (Fig. 2).

In order to examine whether the enhanced ODC activity observed was specifically attributable to the optic nerve crush, the effects of sham-operation and behavioral stress secondary to electrical shock on ODC levels were also examined. No significant changes in retinal ODC were detected following either of these procedures (Fig. 3A). Relatively minor increases in ODC activity were observed in the brain in both experimental groups compared to non-treated control fish (Fig. 3B). These results indicated that the increased ODC levels in the optic nerve-crushed fish are a consequence of the nerve lesion. Further support for this conclusion came from the fact that $O D C$ activity increased in the remaining retina following unilateral eye enucleation (Fig. 4). The pattern of increase of ODC level in the remaining retina following enucleation was similar to that in the optic nerve-crushed fish. The maximum level of the activity at day 5 was about the same as the activity obtained in the control retina of post-crush fish. In contrast to the rapid return of retinal ODC activity to the control level in post-crush fish, the retinal ODC in the unilaterally enucleated fish was still elevated at day 7 , but returned to control levels by 12 days following enucleation.

\section{$O D C$ activities in retinal explants}

NGF is known to stimulate ODC activity in cultured rat superior cervical ganglia ${ }^{18}$ and $\mathrm{PC}-12$ pheochromocytoma cells ${ }^{9}$. Since we had previously demonstrated neurite outgrowth from explanted goldfish retinas, the effect of added NGF on ODC levels on PC and $\mathrm{N}$ retinal explants was examined.

ODC activity increased in vitro within a few hours of the addition of $1 \mu \mathrm{g} / \mathrm{ml}$ of NGF to a FCS-deficient culture medium. The maximum level was attained approximately $6 \mathrm{~h}$ following explantation, both in cultures obtained from $\mathrm{N}$ retinas, as well as $\mathrm{PC}$ retinas, although the per cent stimulation was higher in the PC explants (Fig. 5). Cultures which were kept in FCS-free medium for $72 \mathrm{~h}$ without the addition of NGF did not show an increase in ODC activity.

Dose-dependent responses of retinal cultures to NGF treatments are shown in Fig. 6. Both N and PC explants responded to 0.5 and $1.0 \mu \mathrm{g} / \mathrm{ml} \mathrm{NGF.} \mathrm{ODC} \mathrm{levels} \mathrm{in}$ the treated PC explants were higher than those obtained in $\mathrm{N}$ explants. The enhanced ODC activity observed with NGF treatment $(0.5 \mu \mathrm{g})$ was completely inhibited by the addition of antisera (diluted $1: 20$ ) directed against NGF (Fig. 7). Some non-specific suppression of the NGF effect $(40 \%)$ could be attributed to normal rabbit sera added at the same dilution. 

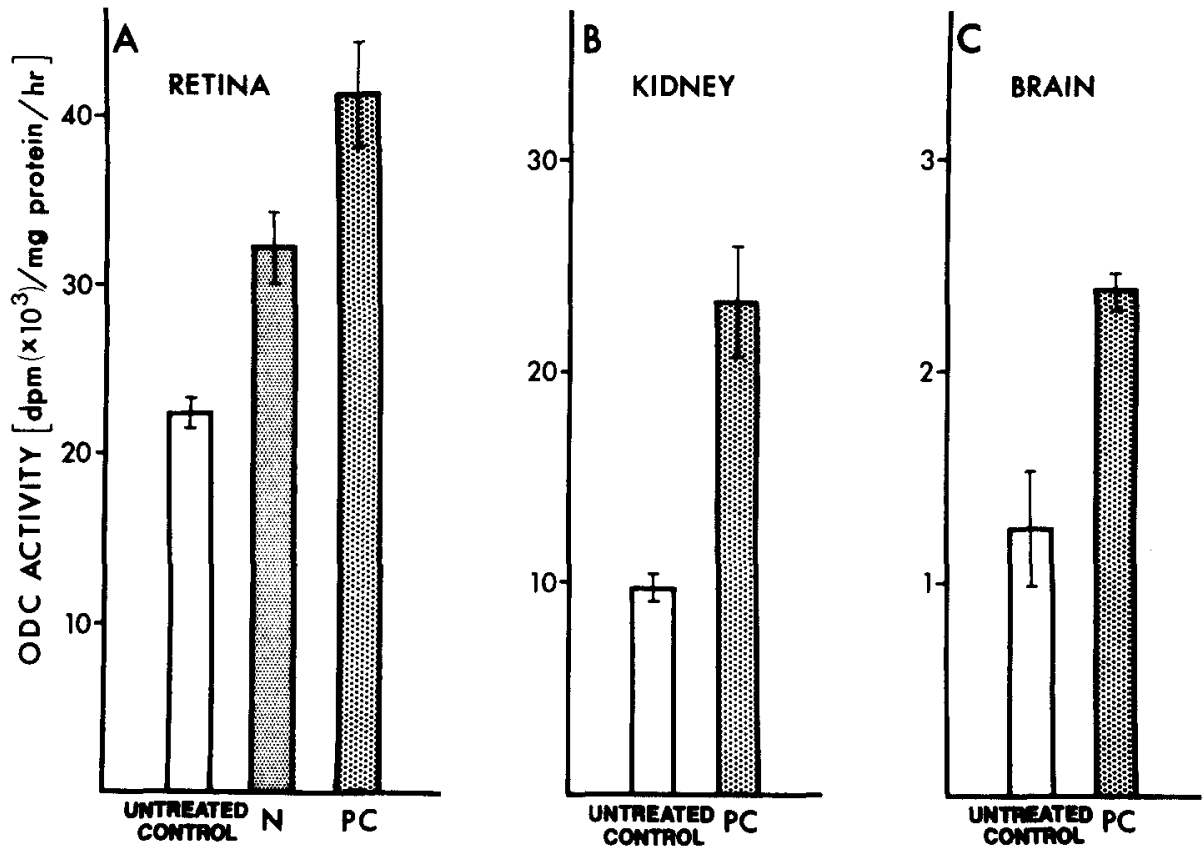

Fig. 2. ODC levels in the retina (A), kidney (B) and brain (C) 4 days following unilateral optic nerve crush. Each column represents mean \pm S.E.M. obtained from $6-9$ groups of pooled tissues from 5 fish. All values in $P C$ fish are significantly higher than those of untreated control fish $(P<0.005)$. The value in $\mathrm{PC}$ retinas is significantly higher than that in the $\mathrm{N}$ retinas $(P<0.005)$.

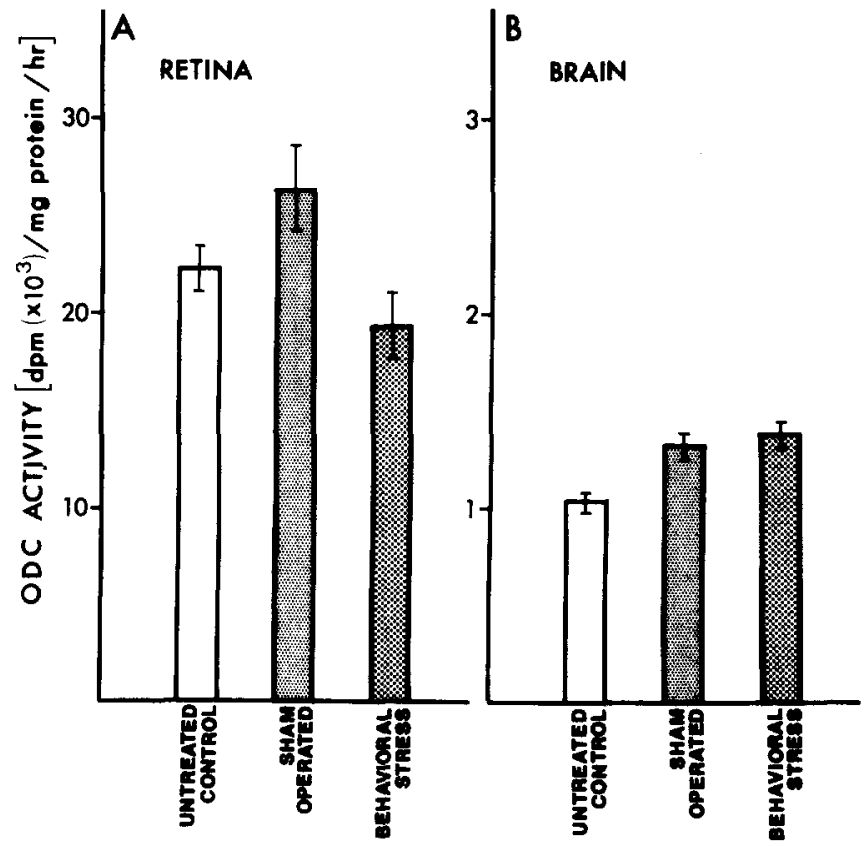

Fig. 3. ODC levels in the retina (A) and brain (B) 4 days following sham operation or behavioral stress. Each column represents mean \pm S.E.M. obtained from 3-6 groups of pooled tissues from 5 fish. The brain values in sham-operated or stressed fish were slightly increased compared with those of untreated control fish $(P<0.05)$. 


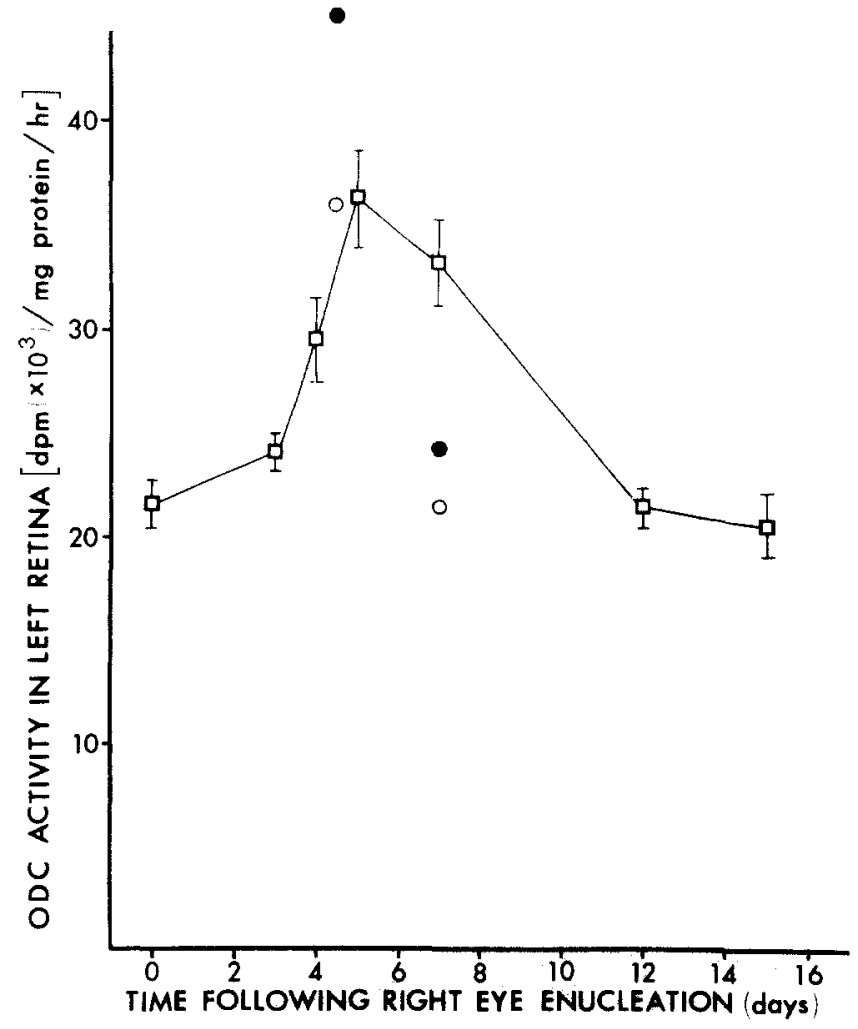

Fig. 4. Retinal ODC levels following unilateral eye enucleation. At various times following eye enucleation, the ODC activity was measured in the remaining retina $(\square)$. Each point represents mean \pm S.E.M. obtained from 3-6 groups of 5 pooled retinas. Values obtained from 4 and 7 days PC(O) and $\mathrm{N}(\mathrm{O})$ retinas from the same batch of fish are inserted in this figure.

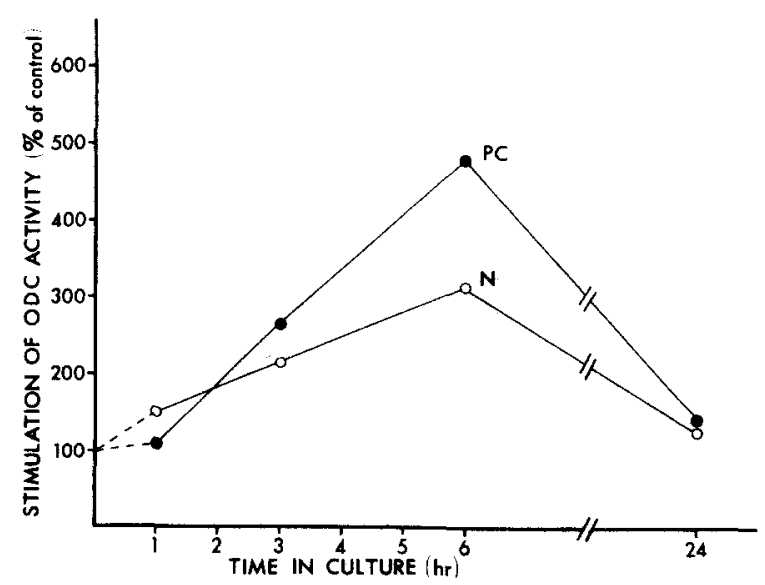

Fig. 5. Stimulation of ODC levels in the retinal explants treated with NGF. Explants obtained from $P C(O)$ and $N(O)$ retinas were treated with NGF $(1.0 \mu \mathrm{g} / \mathrm{ml})$ and the $O D C$ activity was measured at different times following explantation. Each point is an average value obtained from two separate experiments. 


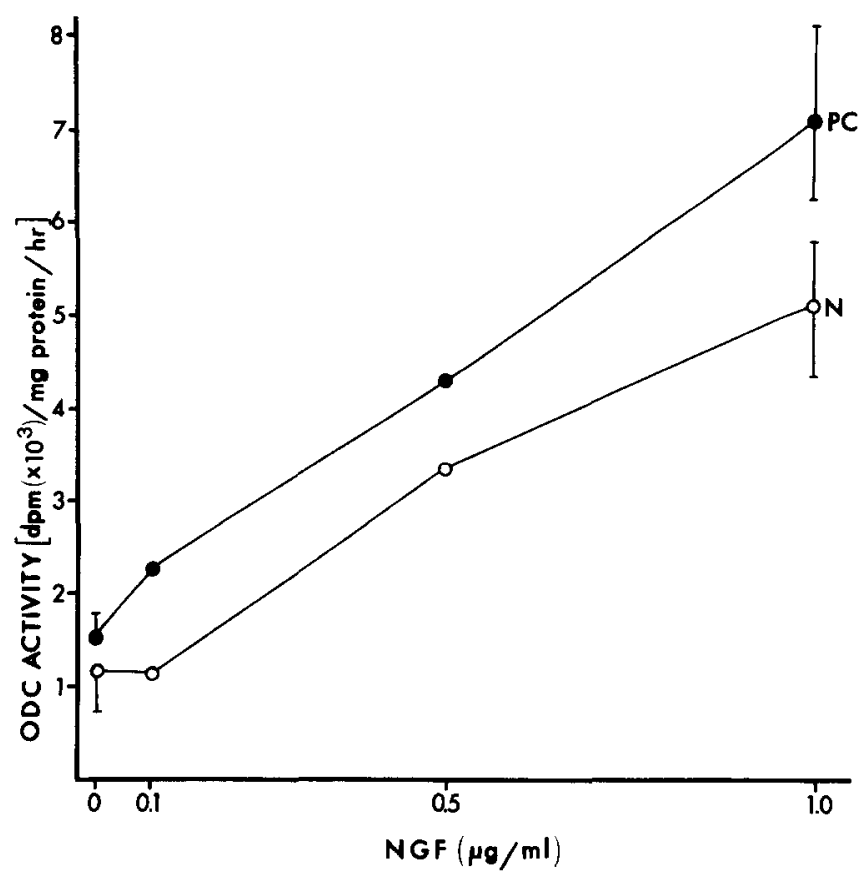

Fig. 6. Dose-dependent stimulation of NGF on ODC levels in the retinal explants. Explants obtained from $\mathrm{PC}(\mathrm{O})$ and $\mathrm{N}(\mathrm{O})$ retinas were treated for $6 \mathrm{~h}$ with $\mathrm{NGF}$ and the ODC activity was measured. Each point is an average value obtained from $2-6$ separate experiments. Vertical lines represent S.E.M. Upon treatment with $1.0 \mu \mathrm{g}$ of NGF, the PC value is significantly higher than the $\mathrm{N}$ value $(P<0.01)$.

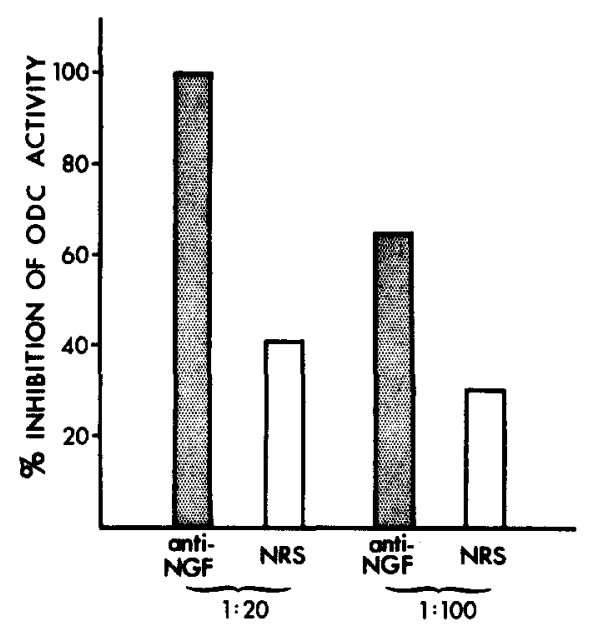

Fig. 7. Effect of anti-NGF sera on ODC levels in the PC retinal explants. Cultures, grown in the absence of FCS, were treated for $6 \mathrm{~h}$ with NGF $(0.5 \mu \mathrm{g} / \mathrm{ml})$ to which either anti-NGF antisera or normal rabbit sera (NRS) matched for immunoglobulin content had been added. Both sera were diluted $1: 20$ or $1: 100$. Per cent inhibition of ODC activity was expressed according to the following equation:

$\frac{\left.\text { (s.a. })_{\text {NGF }}-\text { (s.a. }\right)_{\mathrm{NGF}}+\text { antisera }}{\left.\text { (s.a.) })_{\mathrm{NGF}}-\text { (s.a.) }\right)_{\text {basal }}} \times 100$,

where s.a. (specific activity) was expressed as $\mathrm{dpm} \cdot \mathrm{mg}$ protein ${ }^{-\mathbf{i}} \cdot \mathrm{h}^{-1}$ for the various preparations. 
DISCUSSION

While histological characteristics of the neuronal response to axotomy have long been $\mathrm{known}^{5,8}$, the underlying biochemical mechanisms are not. Using the regenerating teleost visual system, we previously found that the retina on the lesioned side shows an increase in uridine uptake and phosphorylation ${ }^{3,6}$ and that labeled methionine incorporation into tubulin is enhanced within a few days following crush ${ }^{10}$. Isolated PC or $\mathrm{N}$ retinal mRNAs, added to a translating system, have shown that retinal tubulin mRNA is also increased during regeneration ${ }^{4}$. We report here increased ODC activity following optic nerve crush. Unlike the unilateral nature of our previously noted biochemical alterations, the increased retinal activity was bilateral and was elevated in two other organs examined, brain and kidney.

ODC is generally regarded to be the principal rate-limiting enzyme in polyamine synthesis. Polyamines are known to be enriched in nerve tissue compared with other organs, and the fish brain and retina contain particularly large amounts of putrescine $^{28}$, the immediate product of ornithine decarboxylation. When putrescine is injected intraocularly, it is axonally transported to the tectum in regenerating, but not in unlesioned optic nerve ${ }^{13}$. Spermidine and spermine, polyamines for which putrescine is a metabolic precursor, on the other hand, are reported to be transported in normal optic nerve, but more efficiently in newly-regenerated nerve ${ }^{13}$. Increased RNA transport is also reported in the regenerating goldfish visual system ${ }^{14}$. A possible relationship between the RNA and polyamine transport has been proposed ${ }^{13}$, but it should be noted that spermidine rather than putrescine has conventionally been implicated in RNA metabolism².

Rapid and dramatically high increases in ODC activity have been observed in a variety of tissues following physiological or pharmacological stimulation of cell replication ${ }^{24}$. While the precise relation of the polyamines to macromolecular synthesis remains unknown, hypothetical mechanisms generally involve the structural stabilization of RNAs and DNA via electrostatic cross-linking between phosphate acidic functions of the nucleic acids and the bivalent cationic polyamines. Both ODC and its messenger have extremely short half-lives ${ }^{20,26}$, and there is evidence for the presence in tissues of a binding protein (termed 'antizyme') that inactivates the enzyme ${ }^{7,11}$.

Following liver resection, an increase in ODC activity in the remaining liver is seen within $4 \mathrm{~h}$, and is followed by a second increase several hours later ${ }^{12}$. The early change has been attributed to a release of hypophyseal hormones. Increased ODC activity has also been reported in situations in which there is little or no increase in cell numbers, such as muscle hypertrophy ${ }^{25}$.

The widespread nature of the ODC increases seen in the present study suggest that they are linked by a common humoral mechanism. The delay between injury and the maximal response, 4-5 days, is long compared to that seen in the rat following partial hepatectomy $(4 \mathrm{~h})$ even after accounting for the lower metabolic rate of poikilotherms compared to that of mammals. The present experiments indicate that the nerve crush itself, rather than the stress of surgery, leads to the response. Since the increase is 
also seen following enucleation, it would appear unlikely that the lesioned ganglion cell plays a role in the initiation of the response, or that a retrogradely-transported message from the lesioned site could account for the delay between crush and ODC increase. The unilaterally nerve-lesioned and enucleated fish have in common the degenerating optic tract distal to the lesion which could give rise to the variously noted increases by a number of possible mechanisms. For example, autolysis products released from the degenerating nerve might enter the circulation and directly stimulate ODC activity in the various organs. Such products could act indirectly by stimulating release of a hormone which in turn leads to ODC increases as has been noted for growth hormone in the case of liver regeneration. Resorption of the distal stump is accompanied by active infiltration of reactive cells ${ }^{21}$, which could alternatively mediate a generalized ODC response by either a direct or hormone-mediated mechanism. In either case, the slow rise in ODC levels might then reflect the rate of autolysis, resorption or cellular infiltration of the degenerating stump. The consistently higher level of ODC in the PC retina is not easily explained by humoral mechanisms, although it may be that its relative proximity to the degenerating stump facilitates diffusion of more of the putative ODC-stimulating products into the PC retina. Reactive cells in the retina might also contribute to the ODC increase.

It remains possible that the incremental increase in ODC activity in $\mathrm{PC}$ retinas relative to $\mathrm{N}$ retinas is a correlate of the hypertrophic ganglion cell response to axotomy. In previous studies, we demonstrated that PC retinal explants support vigorous neuritic outgrowth in culture, while explants of $\mathrm{N}$ retina do not ${ }^{16}$. That NGF might increase retinal ODC levels was suggested by several previous observations. Greene and McGuire ${ }^{9}$ and MacDonnell et al. ${ }^{18}$ found that NGF addition raised ODC levels in cultured PC-12 cells and in sympathetic ganglia, respectively. Turner et al. ${ }^{30}$ reported that NGF injected intraocularly into goldfish at the time of optic nerve crush accelerated morphometric responses of the retinal ganglion cell to nerve injury.

The enhanced ODC activity seen with NGF addition in the present study was completely suppressed in the presence of antisera specific to NGF (Fig. 7). While normal sera produced a significant inhibition, their effect appeared to be non-specific, as has previously been noted ${ }^{29}$. Time- and dose-dependent responses in ODC activity to NGF were observed in both $\mathrm{PC}$ and $\mathrm{N}$ retinal explants (Figs. 5 and 6), although the stimulation was invariably higher in the $\mathrm{PC}$ retinal explants, perhaps due to increase in the number or affinity of receptors to humoral factors. Fetal calf serum contains factors other than NGF that also increase ODC activity in explants and the ODC response to FCS in $\mathrm{PC}$ retinal explants appears greater than that of $\mathrm{N}$ retinal explants ${ }^{27}$. Insulin, a molecule that shares considerable structural homology with NGF stimulates ODC activity in chick neuronal cell cultures ${ }^{23}$.

We conclude that increases in ODC activity seen following optic nerve crush may reflect events in the retina as well as in the degenerating stump. The degenerative changes could mediate a humoral response upon which there could be an increased responsiveness in the $\mathrm{PC}$ retina of a local nature. The latter interpretation is supported both by the higher response in the $\mathrm{PC}$ retina relative to the $\mathrm{N}$ retina seen in vivo and the enhanced response to NGF seen in PC explants relative to $\mathrm{N}$ explants in vitro. The 
question remains whether either the general or the inferred regional enhancement of ODC activity following nerve crush is epiphenomenal or essential for the recovery of function.

\section{ACKNOWLEDGEMENTS}

This work was supported by NIH Grants NS 13743 and MH 12506. S.K. was supported by the Fukuzawa Memorial Grant of Keio University, Tokyo, Japan and M.S. was supported by a fellowship from the Weizmann Institute of Science, Rehovot, Israel.

We thank Ms. Marianne Andrews for her excellent technical assistance.

\section{REFERENCES}

1 Agranoff, B. W. and Klinger, P. D., Puromycin effect on memory fixation in the goldfish, Science, 146 (1964) 952-953.

2 Bachrach, U., Function of the Naturally Occurring Polyamines, Academic Press, New York, 1973.

3 Burrell, H. R., Dokas, L. A. and Agranoff, B. W., RNA metabolism in the goldfish retina during optic nerve regeneration, J. Neurochem., 31 (1978) 289-298.

4 Burrell, H. R., Heacock, A. M., Water, R. D. and Agranoff, B. W., Increased tubulin messenger RNA in the goldfish retina during optic nerve regeneration, Brain Res., 168 (1979) 628-632.

5 Cragg, B. G., What is the signal for chromatolysis?, Brain Res., 23 (1970) 1-21.

6 Dokas, L. A., Kohsaka, S., Burrell, H. R. and Agranoff, B. W., Uridine metabolism in the goldfish retina during optic nerve regeneration: whole retina studies, J. Neurochem., 36 (1981) $1160-1165$.

7 Fong, W. F., Heller, J. S. and Canellakis, E. S., The appearance of an ornithine decarboxylase inhibitory protein upon the addition of putrescine to cell cultures, Biochim. biophys. Acta (Amst.), 428 (1976) 456-465.

8 Grafstein, B., The nerve cell body response to axotomy, Exp. Neurol., 48 (1975) 32-51.

9 Greene, L. A. and McGuire, J. C., Induction of ornithine decarboxylase by nerve growth factor dissociated from effects on survival and neurite outgrowth, Nature (Lond.), 276 (1978) 191-194.

10 Heacock, A. M. and Agranoff, B. W., Enhanced labeling of a retinal protein during regeneration of optic nerve in goldfish, Proc. nat. Acad. Sci. (Wash.), 73 (1976) 828-832.

11 Heller, J. S., Fong, W. F. and Canellakis, E. S., Induction of a protein inhibitor to ornithine decarboxylase by the end products of its reaction, Proc. nat. Acad. Sci. (Wash.), 73 (1976) 1858-1862.

12 Höltta, E. and Jänne, J., Ornithine decarboxylase activity and the accumulation of putrescine at early stages of liver regeneration, FEBS Lett., 23 (1972) 117-121.

13 Ingoglia, N. A., Sturman, J. A. and Eisner, R. A., Axonal transport of putrescine, spermidine and spermine in normal and regenerating goldfish optic nerves, Brain Res., 130 (1977) 433-445.

14 Ingoglia, N. A. and Tuliszewski, R., Transfer RNA may be axonally transported during regeneration of goldfish optic nerves, Brain Res., 112 (1976) 371-381.

15 Jänne, J., Pösö, H. and Raina, A., Polyamines in rapid growth and cancer, Biochim. biophys. Acta (Amst.), 473 (1978) 241-293.

16 Landreth, G. E. and Agranoff, B. W., Explant culture of adult goldfish retina: a model for the study of CNS regeneration, Brain Res., 161 (1979) 39-53.

17 Lowry, O. H., Rosebrough, N. J., Farr, A. L. and Randall, R. J., Protein measurement with the Folin phenol reagent, J. biol. Chem., 193 (1951) 265-275.

18 MacDonnell, P. C., Nagaiah, K., Lakshmanan, J. and Guroff, G., Nerve growth factor increases activity of ornithine decarboxylase in superior cervical ganglia of young rats, Proc. nat. Acad. Sci. (Wash.), 74 (1977) 4681-4684.

19 Maudsley, D. V., Regulation of polyamine biosynthesis, Biochem. Pharmacol., 28 (1979) 153-161.

20 McCann, P. P., Regulation of ornithine decarboxylase in eukaryotes. In J. M. Gaugas (Ed.), Polyamines in Biomedical Research, John Wiley, New York, 1980, pp. 109-123.

21 Murray, M., Regeneration of retinal axons into the goldfish optic tectum, J. comp. Neurol., 168 (1976) 175-195. 
22 Oka, T. and Perry, J. W., Studies on regulatory factors of ornithine decarboxylase activity during development of mouse mammary epithelium in vitro, J. biol. Chem., 251 (1976) 1738-1744.

23 Parker, K. and Vernadakis, A., Stimulation of ornithine decarboxylase activity in neural cell culture: potential role of insulin, J. Neurochem., 35 (1980) 155-163.

24 Russell, D. H., Ornithine decarboxylase as a biological and pharmacological tool, Pharmacology, 20 (1980) 117-129.

25 Russell, D. H., Shiverick, K. T., Hamrell, B. B. and Alpert, N. R., Polyamine synthesis during initial phases of stress-induced cardiac hypertrophy, Amer. J. Physiol., 221 (1971) 1287-1291.

26 Russell, D. H. and Snyder, S. H., Amine synthesis in regenerating rat liver: extremely rapid turnover of ornithine decarboxylase, Molec. Pharmacol, 5 (1969) 253-262.

27 Schwartz, M., Kohsaka, S. and Agranoff, B. W., Ornithine decarboxylase activity in retinal explants of goldfish undergoing optic nerve regeneration, Develop. Brain Res., 1 (1981) 000-000.

28 Sturman, J. A., Ingoglia, N. A. and Lindquist, T. D., Interconversion of putrescine, spermidine and spermine in goldfish and rat retina, Life Sci., 19 (1976) 719-724.

29 Suda, K., Barde, Y. A. and Thoenen, H., Nerve growth factor in mouse and rat serum: correlation between bioassay and radioimmunoassay determinations, Proc. nat. Acad. Sci. (Wash.), 75 (1978) 4042-4046.

30 Turner, J. E., Delaney, R. K. and Johnson, J. E., Retinal ganglion cell response to nerve growth factor in the regenerating and intact visual system of the goldfish (Carassius auratus), Brain Res., 197 (1980) 319-330. 